\title{
\begin{tabular}{l|l} 
Mibraries & DSpace@MIT
\end{tabular}
}

\author{
MIT Open Access Articles
}

Southern Ocean warming delayed by circumpolar upwelling and equatorward transport

The MIT Faculty has made this article openly available. Please share how this access benefits you. Your story matters.

Citation: Armour, Kyle C., John Marshall, Jeffery R. Scott, Aaron Donohoe, and Emily R. Newsom. "Southern Ocean Warming Delayed by Circumpolar Upwelling and Equatorward Transport." Nature Geoscience, vol. 9, no. 7, 2016, pp. 549-554.

As Published: http://dx.doi.org/10.1038/ngeo2731

Publisher: Nature Publishing Group

Persistent URL: http://hdl.handle.net/1721.1/106534

Version: Author's final manuscript: final author's manuscript post peer review, without publisher's formatting or copy editing

Terms of use: Creative Commons Attribution-Noncommercial-Share Alike 


\section{Southern Ocean warming delayed by circumpolar up- welling and equatorward transport}

Kyle C. Armour ${ }^{*, 1}$, John Marshall ${ }^{1}$, Jeffery R. Scott ${ }^{1}$, Aaron Donohoe ${ }^{2}$ \& Emily R. Newsom ${ }^{3}$

${ }^{1}$ Department of Earth, Atmospheric and Planetary Sciences, Massachusetts Institute of Technology, Cambridge, MA 02139

${ }^{2}$ Polar Science Center, Applied Physics Laboratory, University of Washington, Seattle, WA 98195

${ }^{3}$ Department of Earth and Space Sciences, University of Washington, Seattle, WA 98195

The Southern Ocean has shown little warming south of the Antarctic Circumpolar Current (ACC) over recent decades, and Antarctic sea-ice cover has been modestly expanding1 . Along the northern flank of the ACC, however, the upper ocean has been warming rapidly ${ }^{2,3}$. Using observations and general circulation model simulations, we show that these patterns - of delayed warming south of the ACC and enhanced warming to the north - are fundamentally shaped by the Southern Ocean's meridional overturning circulation: wind-driven upwelling of unmodified water from depth damps warming around Antarctica; greenhouse gas induced heat uptake is largely balanced by anomalous northward heat transport; and heat is preferentially stored along the northern flank of the ACC, where surface waters are subducted. Further, we find that these processes are primarily due to passive advection of the anomalous warming signal by climatological ocean currents; changes in atmospheric and oceanic circulations play a secondary role. These findings suggest that the Southern Ocean responds to greenhouse gas forcing on the timescale over which the deep ocean waters that are upwelled 
to the surface are warmed themselves. It is against this background of gradual warming rather than the rapid warming of the Arctic - that observed Southern Ocean temperature and sea-ice trends must be understood.

The surface of the Southern Ocean (SO), poleward of the ACC, has warmed at a rate of only $0.02 \%$ decade since 1950 , while the global-mean sea-surface temperature (SST) has increased by $0.08^{\circ} /$ decade over this time (Methods). Slow warming of the SO is also a ubiquitous feature of comprehensive general circulation model (GCM) simulations ${ }^{4-9}$. Yet, both paleoclimate observations $^{10}$ and $\mathrm{GCMs}^{7}$ show polar amplification in the Southern Hemisphere in response to climate forcing - with warming in the SO comparable to that in the Arctic - on timescales beyond several millennia. That is, SO warming emerges rather slowly, but may eventually be substantial.

Delayed warming of the SO has been widely attributed to a large thermal inertia arising from very deep mixed layers and storage of heat over great depths ${ }^{4-8,10}$. However, this link rests primarily on pioneering studies of climate change ${ }^{4,5}$ using early GCMs that produced far too much deep convection throughout the $\mathrm{SO}^{11}$ - suggesting that the role of vertical mixing has been overemphasized. Indeed, delayed SO warming robustly occurs within recent generations of GCMs that simulate more realistic convection ${ }^{11}$ and shallow SO mixed layers ${ }^{12}$. Moreover, the deepest mixed layers observed do not coincide with regions of delayed warming but, instead, are found ${ }^{12}$ within and just north of the ACC $\left(40-50^{\circ} \mathrm{S}\right)$ where SSTs have been increasing rapidly $\left(0.11^{\circ} / \mathrm{decade}\right.$ since 1950).

Several other processes have also been suggested to slow the rate of SO warming. Near 
Antarctica, where a persistent halocline exists, freshening of the upper ocean can cool the sea surface by weakening convection and vertical mixing, thus reducing the upward flux of heat from relatively warm waters at depth ${ }^{4,13,14}$. A strengthening and poleward shift of the westerly winds as has been driven by stratospheric ozone depletion ${ }^{15}$ - may also act to cool the region south of the ACC via enhanced Ekman advection of cold surface waters northward ${ }^{15-17}$. Moreover, strengthened surface winds may increase low cloud reflectivity via enhanced emissions of sea spray, and it has been proposed that this effect - together with the direct radiative forcing of stratospheric ozone depletion - has more than offset greenhouse gas (GHG) forcing south of the ACC since the $1980 \mathrm{~s}^{18}$. Additionally, it has been suggested that the extensive SO sea-ice cover itself may slow the rate of warming by shielding the sea surface from radiative forcing ${ }^{19}$. In this study, we consider the processes shaping the SO response within observations and a hierarchy of GCM simulations of varying degrees of complexity. We find that while each of the above processes may play a role in shaping SO temperature trends, particularly on decadal and shorter timescales, the primary source of delayed SO warming is the background ocean circulation.

Great strides have been made in clarifying the dynamics of SO's meridional overturning circulation (MOC) ${ }^{20}$, with its upwelling branch now understood as a balance between wind-driven (Eulerian-mean, $\bar{\psi})$ and eddy-induced $\left(\psi^{*}\right)$ advection: surface wind stresses produce strong circumpolar upwelling south of the westerly wind maximum - near $52^{\circ} \mathrm{S}$ in the zonal mean - and downwelling to the north, while mesoscale eddy fluxes induce a compensating circulation ${ }^{20}$. The resulting, 'residual-mean' flow $\left(\psi_{\text {res }}=\bar{\psi}+\psi^{*}\right)$ is characterized by broad upwelling along sloped isopycnals and northward transport at the surface ${ }^{20,21}$ - as evident in the transport of cold and fresh 
surface waters from the region of seasonal sea ice to subduction zones on the northern flank of the ACC (Fig. 1d). In turn, the SO's residual-mean MOC has become recognized as a key component of the global ocean circulation and of the climate system as a whole ${ }^{20}$. In what follows, we show that the MOC plays a similarly fundamental role in the SO's transient response to climate forcing.

We focus our observational analysis on the period 1982-2012, over which both in situ and satellite observations of SSTs ${ }^{22}$ and sea-surface heat fluxes ${ }^{23}$ (SHFs) are available and ocean temperature measurements ${ }^{24}$ have reasonable coverage within the SO (Methods). Rapid surface warming is seen in zonal bands along the northern flank of the ACC, with slower warming and cooling to the south (Fig. 1a). These SST patterns are mirrored by trends in zonal-mean ocean temperature and depth-integrated heat content (Figs. 1c,d), which show the greatest warming in the vicinity of the ACC $\left(40-50^{\circ} \mathrm{S}\right)$ - consistent with observed trends since the $1950 \mathrm{~s}^{2,3}$.

The net SHF is comprised of turbulent fluxes of sensible and latent heat estimated from bulk formulae, as well as surface radiation derived from satellite observations ${ }^{23}$. Though they are limited in accuracy ${ }^{3,23}$ and spatial coverage (with no observations available under sea ice), SHFs provide valuable insight into the causes of the observed changes. In particular, we see that regions that have warmed strongly have increasingly lost heat to the atmosphere, while regions that have warmed less (or cooled) have increasingly taken up heat (Figs. 1a,b). That is, SHFs appear to have damped - not driven - the spatial pattern of SST trends, reflecting the response of turbulent heat fluxes to local SST changes (Supplementary Fig. S1). Moreover, while surface heat uptake must match ocean heat storage at the global scale, the spatial patterns of SHF trends and heat storage are 
largely opposed over the SO (Figs. 1b,c), implying that changes in meridional ocean heat transport $(\mathrm{OHT})$ - rather than SHFs - have shaped the pattern of warming. Indeed, it appears that a portion of the anomalous heat taken up poleward of the ACC has been transported northward, instead of being stored locally, and that heat has been converged along the northern flank of the ACC. This mirrors the climatological northward transport and subduction of surface waters, consistent with the strong correspondence between the background circulation and the pattern of ocean warming (Fig. 1d). Thus, the observations suggest that anomalous advection of heat by the MOC has damped warming south of the ACC and enhanced warming to the north. However, without a closure of the SO energy budget ${ }^{3,23}$ we cannot accurately determine the magnitude or causes of these apparent OHT changes from the observations alone.

We thus turn to the ensemble of comprehensive GCMs participating in phase 5 of the Coupled Model Intercomparison Project (CMIP5). Driven by historical radiative forcing (Methods) the CMIP5 models broadly capture the observed changes over 1982-2012, with slow surface warming poleward of the ACC (though less cooling than observed) and bands of rapid warming along its northern flank (Fig. 2a). The GCMs simulate somewhat more Southern Hemispheric ocean heat storage $\left(0.64 \pm 0.21 \mathrm{Wm}^{-2}\right)$ than is observed over this period $\left(0.57 \mathrm{Wm}^{-2}\right.$ from ref. ${ }^{24}$; Supplementary Information), possibly due to model deficiencies or to observational biases introduced by infilling data-sparse regions of the ocean ${ }^{2,25}$. Yet, they robustly capture the overall patterns of heat storage, with substantial warming in the vicinity of the ACC and less warming to the south (Figs. 2c,e). Moreover, the spatial patterns of SST and SHF trends are broadly opposed (Figs. 2a,b), indicating that the warming patterns have been driven by anomalous OHT. Local turbulent heat 
flux trends reach several $\mathrm{Wm}^{-2}$ per decade - an order of magnitude larger than radiative forcing changes over this period.

The region of delayed SO warming, poleward of $50^{\circ} \mathrm{S}$, accounts for $60 \pm 10 \%$ of hemispheric surface heat uptake, but only $23 \pm 6 \%$ of hemispheric heat storage (Fig. 2c). That is, less than one third of the anomalous heat taken up at the surface is stored locally; the majority (68 \pm $11 \%$ ) is transported northward, as seen by the robust increase in northward OHT across the ACC (Fig. 2d; Methods). Meanwhile, less than half of the heat stored on the equatorward flank of the $\mathrm{ACC}\left(40-50^{\circ} \mathrm{S}\right)$ is derived from local surface heat uptake; the rest is due to convergence of heat by the ocean. These patterns are broadly consistent with previous modeling studies ${ }^{26,27}$ and the observations (Fig. 1). From an energetics perspective, then, delayed SO warming is primarily driven by increased northward $\mathrm{OHT}$ across the ACC, and enhanced warming in the vicinity of the ACC is driven, in large part, by oceanic heat flux convergence.

A key question then is, what dynamics give rise to these OHT changes? Along and to the south of the ACC, wind-driven gyres contribute little to the total meridional OHT, and thus we can make the approximation: $\mathrm{OHT} \simeq \rho c_{p} \psi_{\text {res }} \Delta T+R$, where $\psi_{\text {res }}$ is the strength of the residual-mean MOC; $\Delta T$ is the vertical temperature difference between northward and southward branches of the MOC; $\rho$ and $c_{p}$ are the density and specific heat of sea water, respectively; and $R$ represents diffusion of heat along isopycnal surfaces. For visual guidance, we calculate $\psi_{\text {res }}$ from NCAR's CCSM4 (contours in Fig. 2e; Methods). As in the observations, there is a striking similarity between this background residual-mean MOC and the pattern of ocean warming, consistent with 
anomalous OHT arising almost entirely from changes in the amount of heat being advected: $\mathrm{OHT}^{\prime}$ $\simeq\left(\rho c_{p} \psi_{r e s} \Delta T\right)^{\prime} \simeq \rho c_{p} \psi_{\text {res }} \Delta T^{\prime}+\rho c_{p} \psi_{\text {res }}^{\prime} \Delta T$; changes in isopycnal diffusion of heat $\left(R^{\prime}\right)$ are relatively small (Fig. 2d).

Several factors could be driving OHT changes over the historical period, including advection of the anomalous temperature signal by the background MOC $\left(\psi_{r e s} \Delta T^{\prime}\right)$ and changes in the MOC induced by either the heat uptake itself or changes in the westerly winds ${ }^{15,26}\left(\psi_{r e s}^{\prime} \Delta T\right)$. To reveal the dynamics underlying delayed SO warming, we consider a series of GCM simulations aimed at isolating the influence of each of these processes. Figures $2 \mathrm{f}-\mathrm{j}$ show the long-term CMIP5 response to GHG forcing alone - at a century after an abrupt quadrupling of $\mathrm{CO}_{2}$. While westerly wind changes (either a strengthening or poleward shift) in these simulations may initially act to cool the SO by advecting cold surface waters northward ${ }^{15-17}$, they ultimately drive enhanced warming of the SO (after several years to several decades) as poleward eddy heat fluxes are increased ${ }^{17,28}$ and relatively warm waters at depth are upwelled at a greater rate $9,28,29$. We can thus be confident that wind changes are not contributing to delayed SO warming at the centennial timescale considered here. Yet, the patterns and mechanisms of SO changes under GHG forcing are remarkably similar to those over the historical period: warming is damped poleward of the ACC and enhanced within familiar zonal bands along its northern flank (Fig. 2f); and while the region poleward of $50^{\circ} \mathrm{S}$ accounts for nearly all (95 $\pm 21 \%)$ of the hemispheric heat uptake over the century (Fig. $2 \mathrm{~h})$, the majority $(67 \pm 5 \%)$ of this heat is advected northward by residual-mean currents and converged equatorward of the ACC (Fig. 2i). This suggests that although wind trends may partially account for differences between the historical simulations (Figs. 2a-e) and observations (Fig. 1) ${ }^{9}$, they 
do not play a critical role in delayed SO warming. Instead, delayed SO warming - driven by anomalous northward OHT - appears to be a fundamental response to GHG forcing.

Further, we can cleanly study the SO's response to GHG forcing, in complete isolation from meddling atmospheric influences, within the framework of an ocean-only GCM. In particular, we simulate the global ocean with the MITgcm (Methods), and produce a climate change scenario by applying a constant radiative forcing of $F=4 \mathrm{Wm}^{-2}$ uniformly over the sea surface (including under sea ice) - approximating an abrupt doubling of $\mathrm{CO}_{2}$. This GHG forcing is prescribed concurrently with constant, annually-repeating sea-surface buoyancy and momentum fluxes that have been derived from a long 'control' simulation (see Methods and ref. ${ }^{30}$ for details). We further specify a spatially-uniform 'radiative feedback' on SSTs anomalies (relative to the control) with value $\lambda=1 \mathrm{Wm}^{-2} \mathrm{~K}^{-1}$, representing the additional energy emitted to space as the surface warms; this value is characteristic of global radiative feedbacks found within the CMIP5 GCMs and derived from satellite observations ${ }^{31}$. Equilibrium would thus be reached when the global-mean SST increases by $F / \lambda=4 \mathrm{~K}$, such that the global radiative response balances the forcing. The magnitude of warming need not be the same everywhere, however. Importantly, because $F$ and $\lambda$ are geographically uniform, and all other sea-surface fluxes are fixed at their control values, any spatial structure in the response can be wholly attributed to oceanic processes.

This ocean-only framework thus mimics GHG-induced climate change in the coupled system under the idealizations that: (i) there is no change in atmospheric heat transport; (ii) atmospheric heat storage can be neglected; (iii) radiative feedbacks are spatially uniform; and (iv) there are 
no changes in surface winds or freshwater fluxes. Remarkably, the ocean-only GCM (Figs. 3ae) captures the principle features of Figs. 1 and 2, including delayed warming poleward of the ACC and enhanced warming within zonal bands along its northern flank (Figs. 3a,e). Because this framework is not able to represent the increase in poleward atmospheric heat transport with global warming, surface heat uptake over the SO is limited by the $4 \mathrm{Wm}^{-2}$ radiative forcing we have applied and is thus smaller in magnitude than that simulated by the CMIP5 GCMs (Fig. 2g). However, the mechanism shaping the SO response is the same: the majority (73\%) of the heat taken up poleward of $50^{\circ} \mathrm{S}$ is advected northward by residual-mean currents and converged equatorward of the ACC (Figs. 3c,d). Delayed SO warming is thus a general feature of the ocean's response to GHG forcing - independent of geographic variations in radiative forcing or feedbacks, trends in atmospheric circulation, or changes in the hydrologic cycle.

What role do ocean circulation changes play in delayed SO warming? To address this question, we consider the response of the ocean-only GCM to a 'passive tracer' forcing (similar in sprit to refs. ${ }^{13,32}$ ), wherein ocean circulation is unchanged and the tracer is advected and mixed from the surface only by climatological ocean processes. The simulation is analogous to the GHG forcing scenario above - the tracer concentration has units of temperature, is initialized with the control temperature distribution, and is forced and damped at the sea surface via uniform $F$ and $\lambda$ - so that directly comparing the passive tracer response (Figs. 3f-j) to the GHG-induced response (Figs. 3a-e) reveals the role of ocean circulation changes. We see that the passive tracer captures the broad features of the SO's response to GHG forcing, with delayed SO warming arising from the advection of the anomalous warming signal by climatological ocean currents. 
Thus, OHT changes can be largely understood as a change in the vertical temperature profile (Figs. 3e,j) on which the climatological residual-mean MOC acts $\left(\psi_{r e s} \Delta T^{\prime}\right)$ : greater warming near the surface (where the flow is northward) than at depth (where the flow is southward) results in anomalous northward OHT that acts to damp warming south of the ACC and enhance warming to the north (Figs. 3d,i). Equivalently, delayed SO warming can be viewed as arising from the equatorward advection of surface waters that have been exposed to GHG forcing, while deep waters that have not yet been modified by GHG forcing are upwelled in their place (Figs. 3e,j). Changes in SO circulation under GHG forcing alone are relatively small (Supplementary Fig. S2), but they act to slightly enhance northward OHT across the $\mathrm{ACC}\left(\psi_{r e s}^{\prime} \Delta T\right.$, which can be inferred from the difference between Figs. 3d and 3i). Additional ocean-only simulations show that anomalies in the MOC and OHT under westerly wind forcing can be substantial on sub-decadal timescales, but that these anomalies diminish relatively quickly; wind forcing ultimately contributes to SO warming after several decades, consistent with previous studies ${ }^{9,28,29}$ (Supplementary Fig. S3).

Two notable differences between the GHG and passive tracer simulations are the depth over which anomalous heat is stored in the ocean (Figs. 3e,j and Supplementary Fig. S2) and the detailed structure of warming near the ACC (Figs. 3a,f). Both can be linked to enhanced stratification of the upper ocean under GHG-induced heat uptake (which is absent under passive tracer uptake). The zonal bands of warming within subduction regions north of the ACC are seen to be driven by a shoaling of winter mixed layers under warming (Supplementary Fig. S4), leading to a reduction in mode water formation ${ }^{33}$ and enhanced heat storage near the surface. These findings suggest that rapid warming along the northern flank of the ACC does not require a wind-driven shift of ocean 
fronts, as has been widely assumed ${ }^{2,16,17,26}$.

Observations and a range of GCM simulations suggest that delayed warming of the SO, poleward of the ACC, is a fundamental consequence of circumpolar upwelling and equatorward transport of surface waters by the SO's residual-mean MOC, and that the anomalous heat taken up at the SO surface is preferentially converged within subduction regions along the northern flank of the ACC. Spatial variations in climatological mixed layer depths, the pattern of radiative forcing, and changes in atmospheric and oceanic circulations all appear to play a secondary role in shaping the SO response. These results suggest that while ocean heat uptake can be understood to curb the pace of surface warming at the global scale, this same reasoning cannot be applied regionally: the slow pace of warming at the SO surface is due to regional ocean dynamics; in turn, heat uptake peaks over the SO because surface warming there is delayed.

These findings further suggest that warming of the SO surface is set by the time it takes for deep ocean waters - originating in the North Atlantic Ocean and ultimately upwelled to the SO surface $\mathrm{e}^{20}-$ to be warmed themselves. This implies a multi-millennial timescale for the SO response to GHG forcing, consistent with GCM simulations ${ }^{6,7}$. Though we may not yet know the full mechanisms driving SO trends, these results suggest that the observed SO cooling and sea-ice expansion over recent decades must be interpreted against a background of very gradual GHGinduced warming - instead of the rapid warming seen in the Arctic. When viewed in this light, it is perhaps not surprising that the SO has cooled for several decades in the face of global warming. 


\section{Methods}

Observations. SST trends since 1950 are calculated from NOAA's Extended Reconstructed Sea Surface Temperature version $3 b$ (ref. ${ }^{34}$ ) as linear trends over 1950-2012. SST trends in the main text are calculated poleward of $50^{\circ} \mathrm{S}$ (the approximate latitude of the ACC), between $50^{\circ} \mathrm{S}$ and $40^{\circ} \mathrm{S}$, and over the global ocean. Linear SST trends over 1982-2012 (Fig. 1a) are calculated from NOAA's Optimum Interpolation Sea Surface Temperature version 2 (ref. ${ }^{22}$ ). Linear SHF trends (Fig. 1b) are calculated from data provided by the Objectively Analyzed air-sea Flux for the Global Oceans Project ${ }^{23}$ (see Supplementary Information). Ocean potential temperature trends and heat storage over 1982-2012 and climatological ocean salinity over 1950-2012 (Fig. 1c,d) are calculated using the Met Office Hadley Centre's EN4 version 1.1 (ref. ${ }^{24}$; see Supplementary Information).

CMIP5 simulations. Figs. 2a-e show CMIP5 'Historical' (1982-2005) simulations and their continuation under RCP8.5 (2006-2012). The simulations are driven historical changes in well-mixed GHGs, aerosols, and stratospheric ozone depletion. Linear trends over 1982-2012 are calculated for SST, SHF and ocean potential temperature, while ocean heat uptake is calculated as the integrated SHF over 1982-2012; anomalous ocean heat storage and OHT are averages over 1982-2012 (see below). Figs. 2f-j show CMIP5 simulations of abrupt quadrupling of atmospheric $\mathrm{CO}_{2}$ above pre-industrial levels. Anomalous SST, SHF, ocean potential temperature and heat storage are calculated from 30-year means centered at 100 years after $\mathrm{CO}_{2}$ quadrupling, while ocean heat uptake is calculated as the integrated SHF over the 100 years; anomalous OHT is an average over the 100 years (see below). To account for model drift, we remove the linear trend over the corresponding years of each model's pre-industrial control simulations from all variables for both the 
historical and $\mathrm{CO}_{2}$ quadrupling simulations. We include all models (12 in total) that provide output for the net sea-surface heat flux (below sea ice), which is necessary to accurately calculate ocean heat uptake and OHT anomalies: ACCESS1-0, bcc-csm1-1, CMCC-CM, CCSM4, CNRMCM5, CSIRO-Mk3-6-0, EC-EARTH, GFDL-ESM2G, MIROC5, MPI-ESM-LR, MRI-CGCM3, and NorESM1-M. The CMIP5 data were downloaded through the Program for Climate Model Diagnostics and Intercomparison's Earth System Grid.

We calculate the anomalous OHT for the CMIP5 models as a residual between the integrated SHF anomaly and ocean heat storage. Uncertainty ranges stated in the text and shown in Figs. 2c,d,h,i are \pm 1 standard deviation across the models. The residual-mean MOC (Figs. 2e,j) was calculated from CCSM4's pre-industrial control simulation; to remove the influence of gyre circulations, we calculate the MOC on isopycnal surfaces and then remap to depth coordinates. The total, residual-mean advection, and diffusive OHT components (black lines on Figs. 2d,i) are standard diagnostics within CCSM4.

Ocean-only GCM simulation. The MITgcm is configured with a hybrid latitude-longitude and cubed sphere configuration, realistic bathymetry, $1^{\circ}$ horizontal resolution and 50 vertical levels. The model is initialized with climatological ocean temperature and salinity data and driven with a repeating annual cycle of atmospheric forcing (see Supplementary Information and ref. ${ }^{30}$ for details). Over this 'spin up' integration, net air-sea fluxes are computed via bulk formulae; for stability, surface salinity is restored on a timescale of 250 days. Once steady-state is achieved, we store all sea-surface buoyancy and momentum fluxes. We then drive the model again by prescribing these stored, steady-state and annually-repeating fluxes (now without bulk formulae or salinity 
restoring), thus producing the 'control' integration against which all climate change simulations are compared. Climate forcings are applied concurrently with these stored fluxes and with a spatiallyuniform 'radiative feedback' on SSTs anomalies (relative to the control), as described in the main text. The SST below sea ice is allowed to evolve according to these same boundary conditions, and is thus able to go above the freezing point. Anomalous SST, SHF, ocean potential temperature and heat storage are calculated at 100 years after $\mathrm{CO}_{2}$ forcing, while ocean heat uptake is calculated as the integrated SHF over the 100 years; anomalous OHT is an average over the 100 years. We calculate the residual-mean MOC for the MITgcm on isopycnal surfaces and then remap to depth coordinates. The MOC shown in Figs. 3e,j is from the MITgem control simulation; anomalies in the MOC under GHG and westerly wind forcing are shown in Supplementary Figs. S2 and S3, respectively.

1. Fan, T., Deser, C. \& Schneider, D. Recent Antarctic sea ice trends in the context of Southern Ocean surface climate variations since 1950. Geophys. Res. Lett. 41, 2419-2426 (2014).

2. Gille, S.T. Decadal-scale temperature trends in the southern hemisphere ocean. J. Clim. 21, 4749-4765 (2008).

3. Rhein, M., et. al. Observations: Ocean. In: Climate Change 2013: The Physical Science Basis. Contribution of Working Group I to the Fifth Assessment Report of the Intergovernmental Panel on Climate Change [Stocker, T.F., et al. (eds.)]. Cambridge University Press, Cambridge, United Kingdom and New York, NY, USA (2013).

4. Manabe, S., Bryan K. \& Spelman, M.J. Transient response of a global ocean-atmosphere model 
to a doubling of atmospheric carbon dioxide. J. Phys. Oceangr. 20, 722-749 (1990).

5. Manabe, S., Stouffer, R.J., Spelman, M.J. \& Bryan, K. Transient responses of a coupled oceanatmosphere model to gradual changes of atmospheric $\mathrm{CO}_{2}$. Part 1: Annual mean response. $J$. Clim 4, 785-818 (1991).

6. Stouffer, R.J. Timescales of climate response. J. Clim. 17, 209-217 (2004).

7. Li, C., von Storch, J.-S. \& Marotzke, J. Deep-ocean heat uptake and equilibrium climate response. Clim. Dyn. doi:10.1007/s00382-012-1350-z (2012).

8. Collins, M., et. al. Long-term Climate Change: Projections, Commitments and Irreversibility. In: Climate Change 2013: The Physical Science Basis. Contribution of Working Group I to the Fifth Assessment Report of the Intergovernmental Panel on Climate Change [Stocker, T.F., D. Qin, G.-K. Plattner, M. Tignor, S.K. Allen, J. Boschung, A. Nauels, Y. Xia, V. Bex and P.M. Midgley (eds.)]. Cambridge University Press, Cambridge, United Kingdom and New York, NY, USA (2013).

9. Marshall, J., et. al. The ocean's role in polar climate change: asymmetric Arctic and Antarctic responses to greenhouse gas and ozone forcing. Phil. Trans. R. Soc. A 372, 20130040 (2014).

10. Masson-Delmotte, V., et al. Information from Paleoclimate Archives. In: Climate Change 2013: The Physical Science Basis. Contribution of Working Group I to the Fifth Assessment Report of the Intergovernmental Panel on Climate Change [Stocker, T.F., et. al. (eds.)]. Cambridge University Press, Cambridge, United Kingdom and New York, NY, USA (2013). 
11. Gent, P.R. The Gent-McWilliams parameterization: 20/20 hindsight. Ocean Modell. 39, 2-9 (2011).

12. Salée, J.-B., et. al. Assessment of Southern Ocean mixed-layer depths in CMIP5 models: Historical bias and forcing response. J. Geophys. Res. Oceans 118, 1845-1862 (2013).

13. Xie, P. \& Vallis, G.K. The passive and active nature of ocean heat uptake in idealized climate change experiments. Clim. Dyn. doi:10.1007/s00382-011-1063-8 (2011).

14. Bintanja, R., van Oldenborgh, G.J., Drijfhout, S.S., Wouters, B. \& Katsman, C.A. Important role for ocean warming and increased ice-shelf melt in Antarctic sea-ice expansion. Nature Geosci. 6, 376-379 (2013).

15. Thompson, D.W., et. al. Signatures of the Antarctic ozone hole in Southern Hemisphere surface climate change. Nature Geosci. 4, 741-749 (2011).

16. Oke, P.R. \& England, M.H. Oceanic response to changes in the latitude of the Southern Hemisphere subpolar westerly winds. J. Clim. 17, 1040-1054 (2004).

17. Fyfe, J.C., Saenko, O.A., Zickfeld, K., Eby, M. \& Weaver, A.J. The role of polewardintensifying Winds on Southern Ocean warming. J. Clim. 20, 5391-5400 (2007).

18. Korhonen, H., et. al. Aerosol climate feedback due to decadal increases in Southern Hemisphere wind speeds. Geophys. Res. Lett. 37, L02805 (2010). 
19. Hutchinson, D.K., England, M.H., Santoso, A. \& Hogg, A.M. Interhemispheric asymmetry in transient global warming: The role of Drake Passage. Geophys. Res. Lett. 40, 1587-1593 (2013).

20. Marshall, J. \& Speer, K. Closure of the meridional overturning circulation through Southern Ocean upwelling. Nature Geosci. 5, 171-180 (2012).

21. Karsten, R.H. \& Marshall, J. Constructing the residual circulation of the ACC from observations. J. Phys. Oceanogr. 32, 3315-3327 (2002).

22. Reynolds, R.W., Rayner, N.A., Smith, T.M., Stokes, D.C. \& Wang, W. An improved in situ and satellite SST analysis for climate. J. Clim. 15, 1609-1625 (2002).

23. Yu, L. \& Weller, R.A. Objectively analyzed air-sea heat fluxes for the global ice-free oceans (1981-2005). Bull. Ameri. Meteor. Soc. 88, 527-539 (2007).

24. Good, S.A., Martin, M.J. \& Rayner, N.A. EN4: quality controlled ocean temperature and salinity profiles and monthly objective analyses with uncertainty estimates.J. Geophys. Res. Oceans, 118, 6704-6716 (2013).

25. Durack, P.J., Gleckler, P.J., Landerer, F.W. \& Taylor, K.E. Quantifying underestimates of longterm upper-ocean warming. Nature Climate Change 4, 999-1005 (2014).

26. Cai, W., Cowan, T., Godfrey, S., \& Wijffels, S. Simulations of processes associated with the fast warming rate of the southern midlatitude ocean. J. Clim. 23, 197-206 (2010). 
27. Frölicher, T.L., et. al. Dominance of the Southern Ocean in anthropogenic carbon and heat uptake in CMIP5 models. J. Clim. 28, 862-886 (2015).

28. Screen, J.A., Gillett, N.P., Stevens, D.P., Marshall, G.J. \& Roscoe H.K. The role of eddies in the Southern Ocean temperature response to the southern annular mode. J. Clim. 22, 806-818 (2009).

29. Ferreira, D., Marshall, J., Bitz, C.M, Solomon S. \& Plumb, A. Antarctic ocean and sea ice response to ozone depletion: a two timescale problem. J Clim. 28, 1206-1226 (2014).

30. Marshall, J., et. al. The ocean's role in the transient response of climate to abrupt greenhouse gas forcing. Clim. Dyn. doi: 10.1007/s00382-014-2308-0 (2014).

31. Donohoe, A., Armour, K.C., Pendergrass, A.G. \& Battisti, D.S. Shortwave and longwave radiative contributions to global warming under increasing $\mathrm{CO}_{2}$. Proc. Nat. Acad. Sci. 111, 16700-16705 (2014).

32. Banks, H.T. \& Gregory, J.M. Mechanisms of ocean heat uptake in a coupled climate model and the implications for tracer based predictions of ocean heat uptake. Geophys. Res. Lett. 33, L07608 (2006).

33. Downes, S.M., Bindoff, N.L. \& Rintoul, S.R. Impacts of climate change on the subduction of mode and intermediate water masses in the Southern Ocean. J. Clim. 22, 3289-3302 (2009).

34. Smith, T.M., Reynolds, R.W., Peterson, T.C. \& Lawrimore, J. Improvements NOAAs Historical Merged Land-Ocean Temp Analysis (1880-2006). J. Clim. 21, 2283-2296 (2008). 
Competing Interests The authors declare that they have no competing financial interests.

Correspondence Correspondence and requests for materials should be addressed to KCA (email: karmour@mit.edu). 


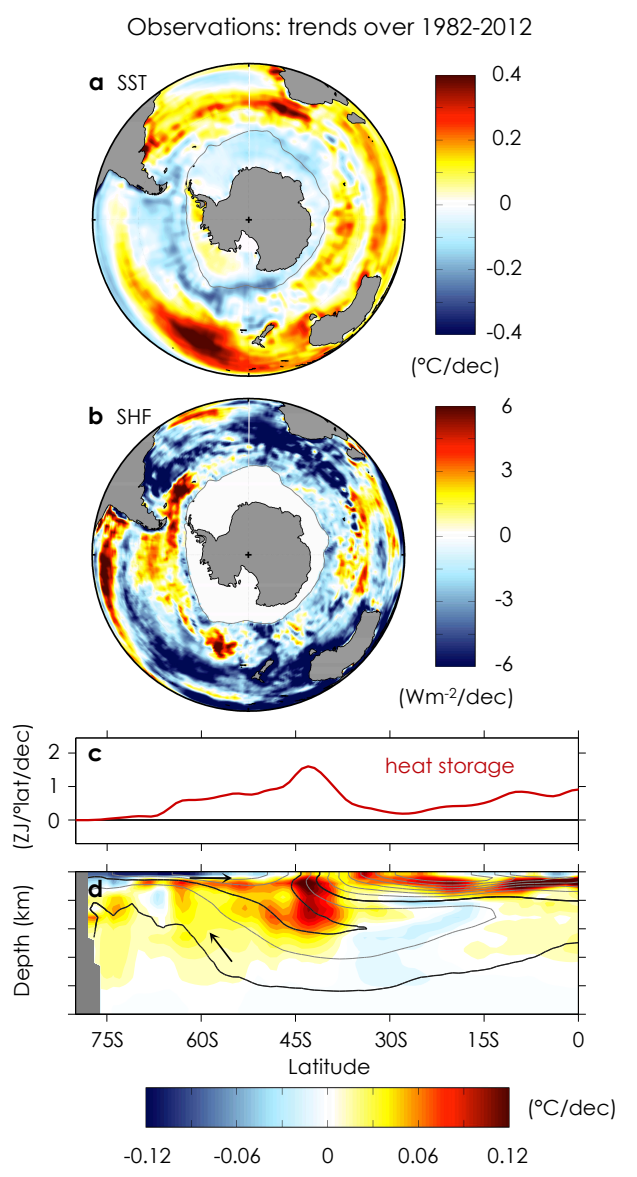

Figure 1: Observed trends over 1982-2012. a, Annual-mean sea-surface temperature trend; b, Net sea-surface heat flux trend (positive into ocean); c, Zonally and full-depth integrated ocean heat content trend; d, Zonal-mean ocean potential temperature trend, with contours of climatological ocean salinity in intervals of 0.15 psu (grey lines). Arrows indicate the orientation of the residualmean MOC following ref. ${ }^{21}$, along 34.4 and 34.7 psu contours (black lines). Grey line in a and b shows maximum winter sea-ice extent from ref. ${ }^{23}$. 
CMIP5: trends over 1982-2012
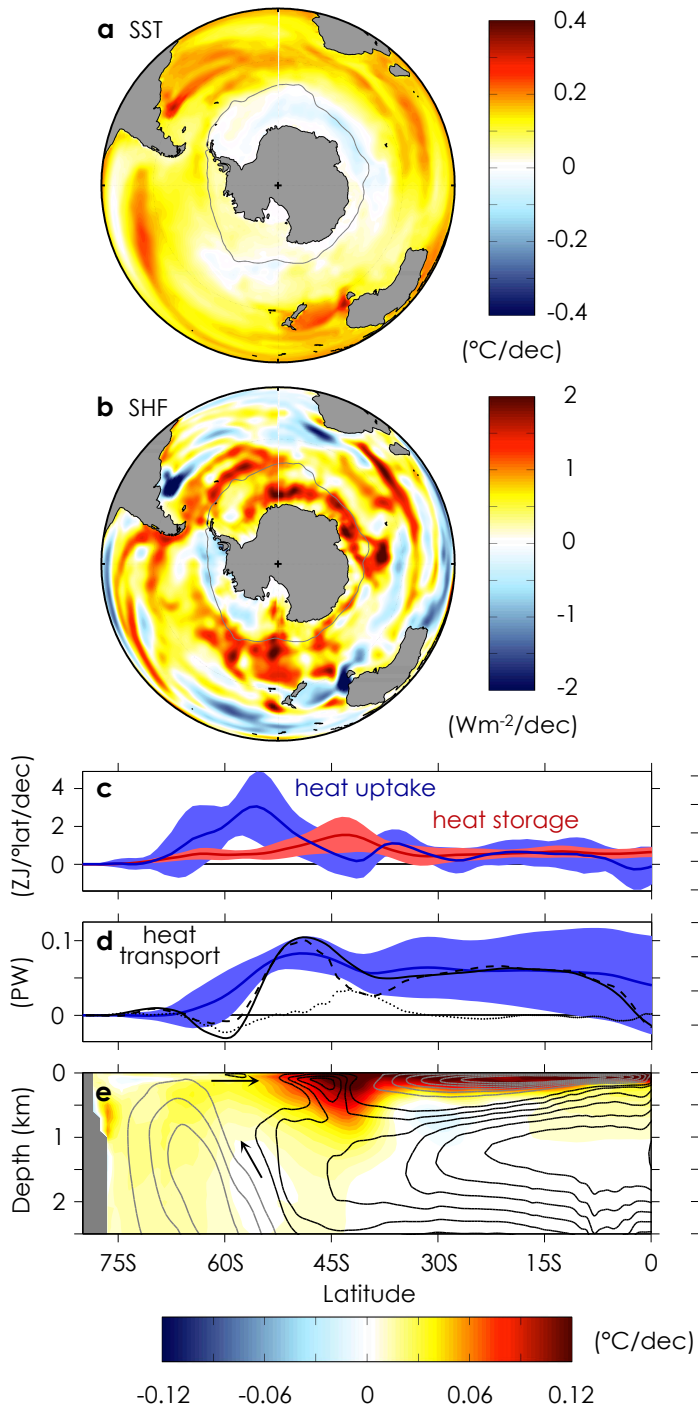

CMIP5: anomalies 100 yrs after $\mathrm{CO}_{2}$ quadrupling
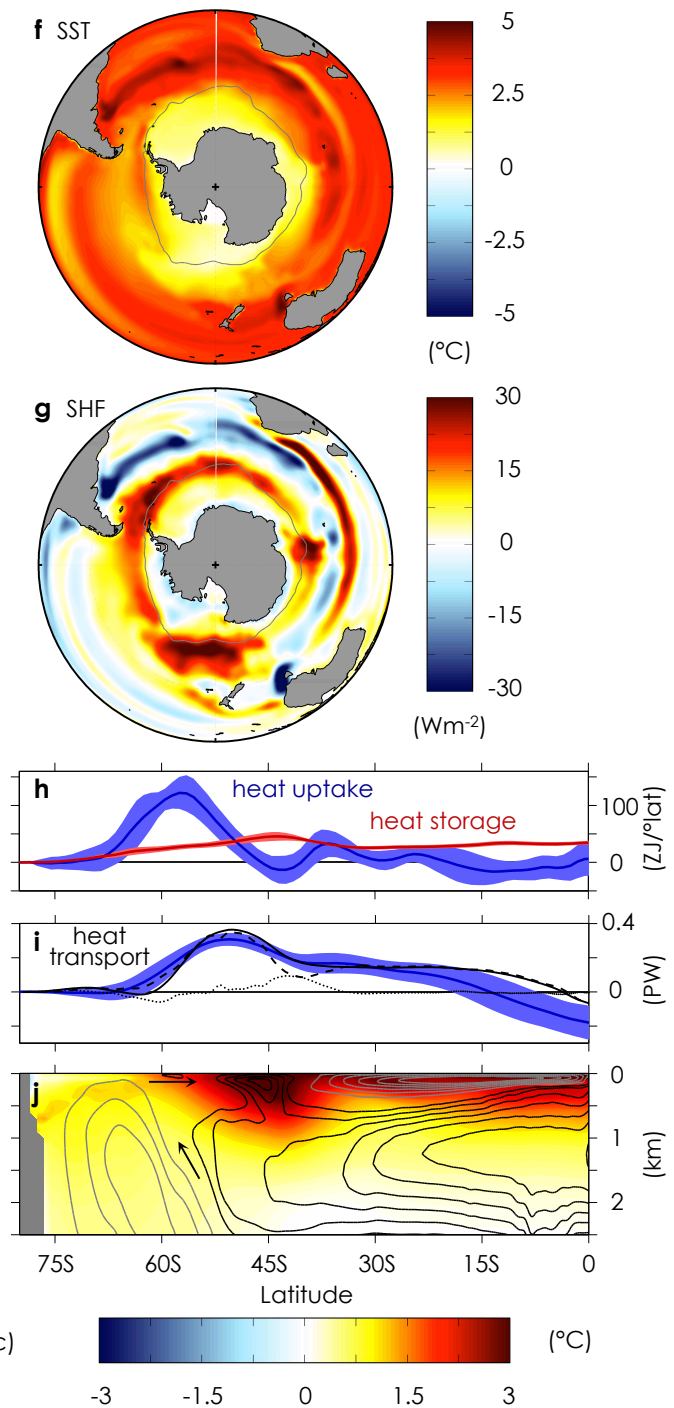

Figure 2: CMIP5-mean trends over 1982-2012 (left) and response to $\mathrm{CO}_{2}$ forcing (right).

a, Annual-mean sea-surface temperature trend; b, Net sea-surface heat flux trend (positive into ocean); c, Zonally integrated average sea-surface heat flux (blue) and full-depth ocean heat content trend (red); d, Anomalous OHT for CMIP5-mean (blue) and CCSM4 (black; solid, dashed and dotted lines show total, residual-mean advection, and diffusion, respectively); e, Zonal-mean ocean potential temperature trend, with contours showing the MOC from CCSM4 (black contours show positive circulation in $4 \mathrm{~Sv}$ increments, gray contours show negative circulation in $-4 \mathrm{~Sv}$ increments); f-j, As in a-e, but anomalies over 100 yrs in response to abrupt $\mathrm{CO}_{2}$ quadrupling. Grey line in $\mathbf{a}, \mathbf{b}, \mathbf{f}$ and $\mathbf{g}$ shows maximum winter sea-ice extent, as in Fig. 1. Shading in $\mathbf{c}, \mathbf{d}, \mathbf{h}$ and $\mathbf{i}$ shows the \pm 1 standard deviation range across the CMIP5 models. 
MITgcm: anomalies 100 yrs after $4 \mathrm{Wm}^{-2}$ forcing MITgcm: anomalies 100 yrs after $4 \mathrm{Wm}^{-2}$ passive forcing
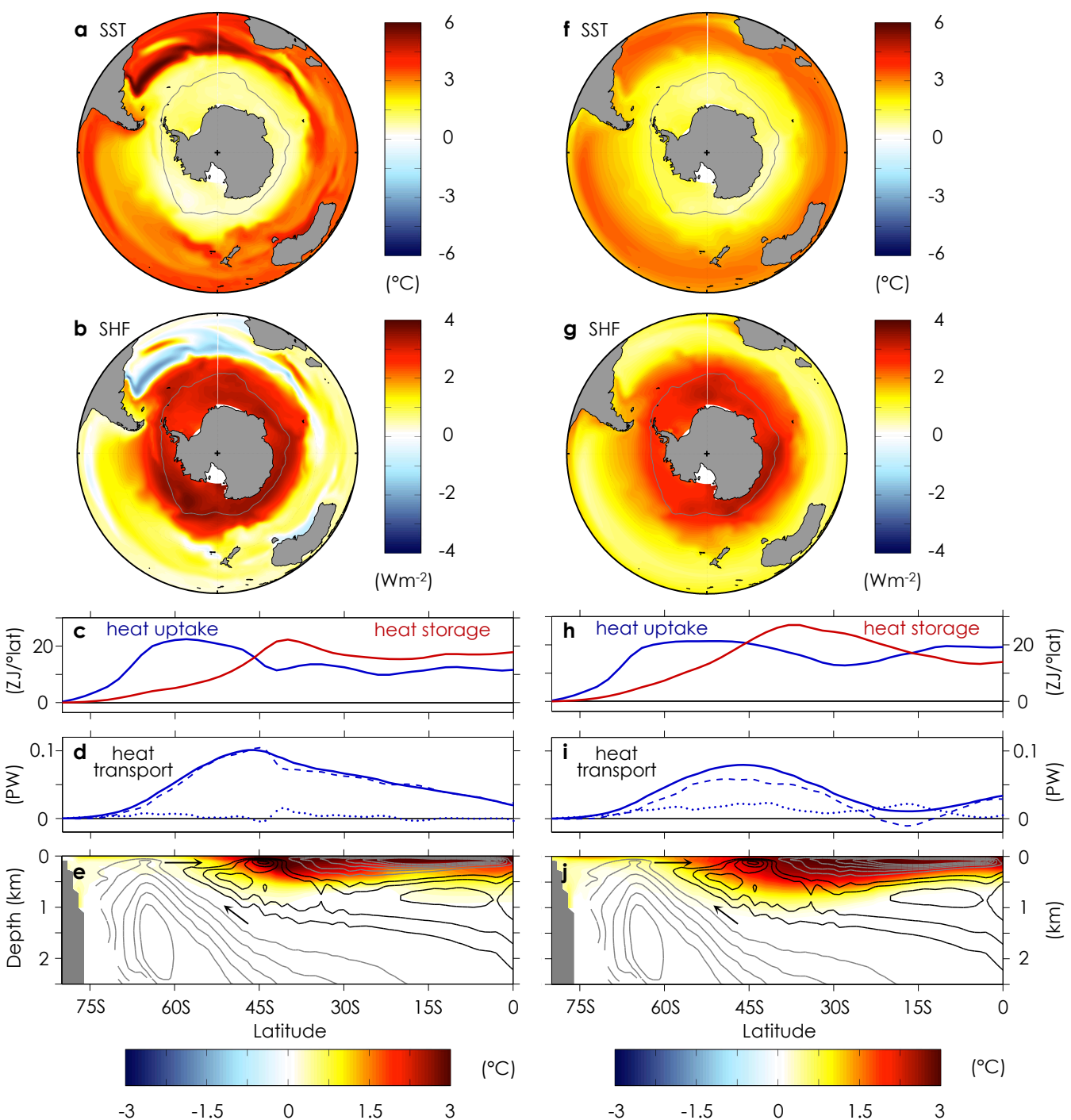

Figure 3: MITgcm response to GHG forcing (left) and passive tracer forcing (right). a, Annual-mean sea-surface temperature anomaly; b, Net sea-surface heat flux anomaly (positive into ocean); c, Zonally integrated average sea-surface heat flux anomaly (blue) and full-depth ocean heat content anomaly (red); d, Anomalous OHT (solid, dashed and dotted lines show total, residual-mean advection, and diffusion, respectively); e, Zonal-mean ocean potential temperature anomaly, with contours showing the MOC from the control simulation (black contours show positive circulation in $2 \mathrm{~Sv}$ increments, gray contours show negative circulation in -4 Sv increments); $\mathbf{f - j}$, As in $\mathbf{a}-\mathbf{e}$, but for the passive tracer simulation. Grey line in $\mathbf{a}$ and $\mathbf{b}$ shows maximum winter sea-ice extent, as in Fig. 1. 